Check for updates

The BMJ

Cite this as: $B M J 2020 ; 370: m 2736$ http://dx.doi.org/10.1136/bmj.m2736 Published: 08 July 2020

\section{Public health and spiritual health: five minutes with ... Gina Radford}

\section{The former deputy chief medical officer for England and vicar of South Brent and Rattery tells Abi Rimmer how her past and present roles have collided during the pandemic}

\section{Abi Rimmer}

“For the first half of my career I was looking after people's physical and mental health, and now I'm looking after their spiritual health. I honestly thought that I'd left my old world behind. For it to come back, and then having to inhabit both worlds at the same time, has been very interesting.

“At the start of the pandemic I felt a huge pull to go back [to medicine] because that's the world I'm used to. I thought that I should be going back and offering my help to the health department. But, once I got involved in national work providing guidance to the Church of England, I realised that this is where I'm meant to be, bringing both worlds together. It's been very interesting, wearing both hats at the same time.

"For example, I've done a lot of media interviews over the past few weeks talking exclusively about public health, but I always wear my dog collar because that's who I am. While some people might be thinking, 'She's a vicar, what does she know about public health?' in other ways I think it's been very helpful. I'm not coming at it from a political or government point of view-I'm just taking it as I find it. In some ways that's been quite liberating.

"We're all very conscious of the impact that this pandemic has had on people. I'm very aware of the direct impact it's had on people's physical, mental, and spiritual health and the importance that faith has in these sorts of situations. The church is addressing-and needs to address-the huge inequality on which this pandemic has starkly shone a spotlight. This is both in terms of the way it has affected people and in recognising that the most deprived people will be left with the worst legacy.

"This pandemic is not just about the direct physical impact it has had on people's health or the inconvenience it has brought. There will be some lasting and very challenging legacies that, as a society, we're going to have to grapple with.

"The medical profession has an important role in highlighting these issues, because doctors are trusted and can speak out in a way that isn't political. They also need to make the narrative clear around the links between inequality, racial discrimination, and people's health and wellbeing. Doctors need to have a very strong advocacy role in all of this.

"They also have an important role to play in ensuring that people who are now suffering because services were directed away from them during the pandemic are helped and supported as much as possible.

"We have a huge legacy of those who have not received appropriate care and support who now will suffer, and that is an absolute tragedy." 